appearance of multiple cutaneous infections. Blood culture and culture from the pustules revealed haemolytic streptococci group $A$. The baby recovered after treatment with ampicillin.

Disseminated intravasoular coagulation has been found to occur in connexion with septic shock. ${ }^{4}$ Both thromboplastic material and fibrinolytic activators are most probably released as a consequence of endothelial damage to bacterial toxins. ${ }^{5}$ In most such cases therefore both the coagulation and fibrinolytic systems will be activated. In the present case the coagulation system was activated as shown by the decreased platele count and the decreased levels of prothrombin, fibrinogen, antithrombin III, and $\alpha$, -macroglobulin. Soluble fibrin monomers were demonstrated and fibrin thrombi were found post mortem in the pulmonary and renal vessels. Extremely high levels of AHF antigen have been found in conditions with severe tissue damage. ${ }^{6}$ A discrepancy between the antigen level and the AHF activity of the same degree as in the present case has been demonstrated in patients with signs of an activated coagulation system during pregnancy ${ }^{7}$ and has been proposed as an early sign of a pathologically activated coagulation system.

The patient had, however, also signs of a markedly activa:ed fibrinolytic system with increased fibrinolysis, extremely high levels of fibrinogen degradation products of low molecular weight, indicating complete degradation of fibrinogen, and a very low fac'or V level. Alpha:-macroglobulin binds both thrombin and plasmin, and very low levels are seen when both these proteolytic enzymes are present, as in this patient. Because the patient showed an activated fibrinolytic system, no tranexamic acid was administered after the first dose. She was given dextran in order to prevent further platelet aggregation and fibrin depasition, and freshly frozen plasma and fresh blood were given to replace the coagulation factors.

The vaginal flora in pregnant women sometimes contains haemolytic streptococci. These are usually commensals, but a few groups of streptococci are known to be able to cause malignant infections in puerperal and neonatal subjects. Group B streptococc are the most commonly encountered in the vagina, but the question whether pregnant carriers. should generally receive preventive penicillin treatment is not yet settled. On the other hand, during late pregnancy the presence in the birth canal of haemolytic streptocooci of group $A$, which more consistently occasion severe infections, is in our opinion of much graver significance. The finding of group A streptocooci in women before parturition should be seriously considered as an invariable indication for proper preventive penicillin treatment.-We are, etc.,

G. GENNSER S. OHRLANDER

Department of Obstetrics and Gynaecology

A. Cederberg

Department of Bacteriology

U. HEDNER

Coagulation Laboratory, Allmänna Sjukhuset,

Malmö, Sweden

MoCracken, G. H., Fournal of Pediatrics, 1973 82, 703.

W. J., American fournal of Obstetrics $1974,118,296$.

F. New England fournal of Medicine 1973, 289, 43.

Coagulation. G., Disseminated Intravascular Disease. New York, Hoeber Medical Division 1965.
Nilsson, I. M., Haemorrhagic and Thrombotic Diseases. London, Wiley. In press. Holmberg, L., Nilsson, I. M.. Scandinavian Nilssonal of Haematology, 1974, 12, 221. cologica Scandinavica Acta Obstetricia et GyneIn press.

\section{Cervical Plasma Cell Population in Infertile Patients}

SIR,-In their article on increased $\operatorname{Ig} A$ containing plasma cells in the cervices of infertile patients Mr. R. B. Hutcheson and his colleagues (28 September, p. 783) make no mention as to whether they found a relationship with the result of the postcoital (Sims) test and/or invasion (KurrockMiller) test.

In this olinic we find a definite group of patients who evince "cervical hostility" as judged by these tests. It would be of great interest to know whether it is this same group of patients who have an increase in plasma cells containing IgA.-I am, etc.,

\section{ROSALIND HINTON}

Female Subfertility Clinic

Avon Area Health Authority (Teaching), Central Health Clinic, Bristo

\section{Gaps in Medical Research}

SIR,-Last year the Board of Science and Education of the B.M.A. set up a special panel to study gaps in medical research, with particular reference to common and everyday maladies, and I was appointed to chair this multidisciplined group.

We are interpreting our terms of reference broadly and are interested in prevention as well as cure, and in some aspects of human behaviour in relation to health as well as common problems in the delivery of care. In enabling us to fulfil our task we feel it would be helpful to have views from members of the professions engaged in the health services as well as from consumers of medical care. In particular, we would like to hear of problems which, while they do not necessarily threaten life, are serious in the sense that they are common and cause inconvenience or pain and into which medical research is needed.

Evidence from individuals or groups would be most weloome and should be sent to the Secretary of the Board of Science and Education of the B.M.A., B.M.A. House, Tavistock Square, London WC1H 9JP.-I am, etc.,

London W.C.1

E. M. BACKETT

\section{"Continuing Clinical Responsibility"}

SIR,-Unlike my colleague Mr. F. A. Howard (5 Oatober, p. 49) I found it impossible to complete the ill-prepared questionnaire I received from the Joint Working Party on the Terms of Employment of Senior Hospital and Medical and Dental Staff. I would, however, like to make some comments from the point of view of a senior consultant about the contents of his letter. The senior hospital staffs in the N.H.S. are the only group of doctors who are not paid the "rate for the job." After a long and arduous training a doctor is appointed as a consultant in charge of patients. One would assume that now he was fully trained, but this cannot be the case as he is paid at the beginning of his appointment nearly $£ 3,000$ a year less than when he is senior. No trade union would accept lower pay for its skilled workers just because they are younger; why do we accept it? At a recent meeting in the south of England I was told that it was now impossible for a young consultant to buy a house in the district as he did not earn enough to get a mortgage. It was suggested that an approach was to be made to the hospital to provide caravans in the hospital grounds for the young consultants to live in. I find this state of affairs not only unjust but almost unbelievable, and one wonders just how long we are going to tolerate it. -I am, etc.,

Doncaster

P. H. Beales

SIR,-The questionnaire recently sent to consultants from the Joint Working Party on consultants' terms and conditions, with the blessing, albeit qualified, of our own representatives, must surely set the alarm bells ringing. The potential utilization by the Government of the statistics thus collected could well be as follows: (1) average number of "out of normal hours" worked per week $=\mathrm{X}$; (2) suggested appropriate total average remuneration $=\mathbf{R}$; (3) therefore $\mathrm{R}-(\mathrm{X} \times \mathrm{F})=$ Basic Salary where $\mathrm{F}=$ the rate per hour for "additional work."

Clearly the result, essentially a system of piecework overtime, would be that those specialties with a large element of "out of normal hours" work or time "on call" would achieve a level of remuneration which might be just acceptable, but many, perhaps the majority, would attract no more than an unacceptably low basic salary. There will be those who will argue that specialties with a large "out of normal hours" commitment should indeed attract a higher level of remuneration than others, but there are less obvious factors perhaps only immediately appreciated by the practitioner of any given specialty.

Personally, I think I would feel physically and mentally exhausted after a "normal" day's work with psychiatric patients, for example, and speaking as a radiologist it is arguable that a high concentration of work load within the working day, with perhaps 100 or more signed clinical decisions, combined with potential radiation exposure and the physical work of modern special techniques is at least as demanding as the routine in other specialties. It is to be noted, also, that even outside teaching centres the "major" specialties do generally have some level of supporting staff, whereas in other specialties this is unknown and the consultants perforce carry every last item of the work load of the unit till the day they retire. It is suggested that we must be wary of a "divide and conquer" policy and ooncentrate on the objective of a realistic flat rate of remuneration for each career grade in the hospital service, leaving other features of each specialty to determine which an individual chooses to pursue.

The arguments against "piecework" are too well known to require repetition here, but it is particularly worth noting the implications in relation to the existing pension system, whereby any practitioner on basic salary plus "piecework" can optimize his pension only by working hardest in one of his last three years.-I am, etc.,

W. L. MUNRO

Radiological Unit,
The Infirmary, Kilmarnock 